\title{
PENERAPAN ALGORITMA K-MEANS UNTUK MENGETAHUI TINGKAT TINDAK KEJAHATAN DAERAH PEMATANGSIANTAR
}

Devi Gultom, Hotma Dame Tampubolon, Luvita Yolanda Hutabarat, Fikrul Ilmi R H Zer, Dedy Hartama

\author{
Program Studi Teknik Informatika, STIKOM TUNAS BANGSA \\ Jl.Jend. Sudirman Blok A, No.1,2 dan 3, Kota Pematangsiantar, Sumatera Utara \\ devigultom30@gmail.com, hotmatampubolon26@gmail.com, luvitahutabarat04@gmail.com, \\ fikrulilmizeregmail.com, dedyhartama@amiktunasbangsa.ac.id
}

\begin{abstract}
Crime is now a concern and concern for the community, especially those in the Pematangsiantar Region. Acts of crime that often occur are murder, theft, drugs, rape. With the rampant crime in Pematangsiantar City, it is necessary to group each region using the $\mathrm{K}$ Means algorithm. The data source in this study is a collection of various documents of information Criminal Acts by Pematangsiantar Police Law. The data used in this study are data from 2019 consisting of 6 Districts. In this study, the K-Means algorithm is used to find out areas that have high crime rates and low crime rates areas.
\end{abstract}

Keywords - Crime, K-Means, Clustering, Data Mining

Abstrak - Kejahatan saat ini menjadi perhatian dan ke khawatiran bagi masyarakat terutama yang ada di Wilayah Pematangsiantar. Aksi kejahatan yang sering terjadi ialah pembunuhan, pencurian, narkoba, Pemerkosaan. Dengan maraknya kejahatan di Kota Pematangsiantar maka di perlukan pengelompokkan tiap daerah menggunakan algoritma K-Means. Sumber data pada penelitian ini merupakan kumpulan dari berbagai dokumen-dokumen keterangan Aksi Kriminalitas oleh Hukum Polres Pematangsiantar. Data yang digunakan pada penelitian ini adalah data dari tahun 2019 yang terdiri dari 6 Kecamatan. Dalam penelitian ini algoritma K-Means digunakan untuk mengetahui daerah yang memiliki tingkat kejahatan tinggi dan daerah tingkat kejahatan rendah.

Kata Kunci - Kejahatan, K-Means, Clustering, Data Mining

\section{PENDAHULUAN}

Tindakan kejahatan merupakan tindakan yang bersifat negatif. Seringkali, tindakan ini merugikan banyak pihak dan pelaku tindakannya disebut sebagai seorang kriminal. Kriminalitas atau tindak kriminal segala sesuatu yang melanggar hukum atau sebuah tindak kejahatan.Tindak kejahatan saat ini yang menjadi perhatian dan pemberitaan di berbagai media massa maupun elektronik. Kejahatan sering terjadi seperti pembunuhan, perampokan, pemerkosaan, dan lain sebagainya yang dapat mengkhawatirkan masyarakat [1]. Salah satu metode yang digunakan dalam data mining adalah Clustering K-Means. Clustering K-Means merupkan salah satu algoritma data clustering non hirarki yang berusaha mempartisi data yang ada kedalam bentuk satu atau lebih cluster[2].
Pada Penelitian Sinta Maulina Dewi, dkk dengan judul Analisa Metode K-Means pada Pengelompokan Kriminalitas Menurut Wilayah menjelaskan tentang metode k-means untuk menganalisis nilai clustering yang paling rendah, hal ini dikarenakan kmeans dapat mengelompokkan data dengan jumlah yang cukup besar dalam waktu komputasi yang relatif cepat dan efisien[1].

Dalam Penelitian Johan Wisma Anggoro, dkk menggunakan tiga metode cluster Analysis, yaitu metode Kernel Density, metode K-Means dan metode K-Medoids. Metode Kernel Density digunakan untuk menganalisis titik kejadian curanmor untuk menentukan tingkat kerawanan. Metode KMeans dan metode KMedoids digunakan untuk menentukan tingkat kerawanan dan jumlah kejadian. 
Pada penelitian ini data kriminal ditiap Kecamatan di Pematangsiantar akan dijadikan bahan untuk penerapan data mining. Dalam melakukan clustering, data yang telah diperoleh akan dihitung berdasarkan jumlah data kriminalitas pada tahun 2019 menurut 6 Kecamatan di Wilayah Hukum Polres Pematangsiantar Penulis menggunakan Data Mining untuk mengelolah data tindak kejahatan dengan tujuan mengelompokkan data kejahatan untuk menentukan cluster tingkat kejahatan tinggi dan cluster tingkat kejahatan rendah.

\section{METODE PENELITIAN}

\section{A. Data Mining}

Data Mining sering digunakan sebagai analisis data, statistik, dan proses untuk mendapatkan informasi yang berguna dari gudang basis datayang besar, yang dapat juga diartikan sebagai pengekstrakan informasi baru yang diambil dari data besar yang membantu dalam pengambilan keputusan (Knowledge Discovery). Pendekatan dasar dalam data mining adalah untuk meringkas data dan untuk mengekstrak informasi berguna yang masuk akal dan sebelumnya tidak diketahui.

Data mining dibagi menjadi 2 kategori utama, yaitu:

1. Descriptive mining, tahapan untuk menemukan karakteristik penting dari data dalam satu basis data.

2. Predictive, tahapan untuk mempelajari bagaimana pattern design dari data set yang berupa variabel[3].

Data mining merupakan inti dari proses Knowledge Discovery in Database (KDD). KDD dapat dikatakan sebagai penyelesaian masalah dengan menganalisa data yang ada pada database dengan data tersimpan secara elektronik dan pencariannya dilakukan otomatis seperti pada computer[4]. Tahapan proses KDD seperti pada Gambar 1

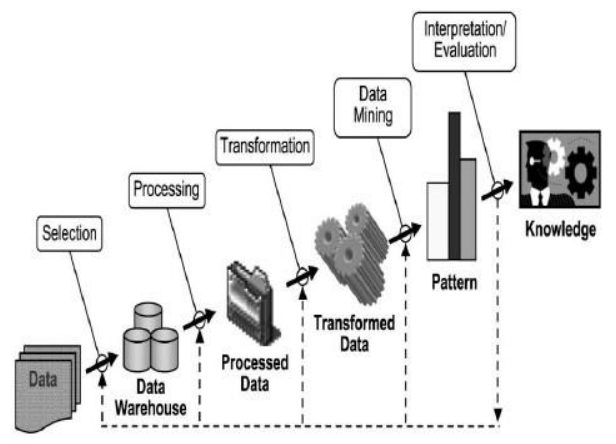

Gambar 1. Tahapan proses KDD

\section{B. Algoritma K-Means}

K-Means merupakan salah satu algoritma Clustering yang masuk dalam kelompok Unsupersived Learning yang digunakan untuk membagi data menjadi beberapa kelompok dengan system partisi. Algoritma ini menerima masukan berupa data tanpa label kelas. Pada setiap cluster terdapat titik pusat (centroid) yang mempresentasikan cluster tersebut. Secara sederhana algoritma K-Means dapat dijelaskan sebagai algoritma data mining yang digunakan untuk menyelesaikan masalah pengelompokkan (Clustering).

Langkah-langkah algoritma K-Means dapat dijelaskan sebagai berikut[7]:

1. Tentukan jumlah Cluster (k) pada data set.

2. Tentukan titik pusat (Centroid) secara random.

$$
V_{i j}=\frac{1}{N_{i}} \sum_{k=0}^{N_{i}} X_{k j}
$$

Keterangan:

$\mathrm{V}_{\mathrm{ij}} \quad=$ Centroid rata-rata cluster ke-i untuk variable ke-j

$\mathrm{N}_{\mathrm{i}} \quad$ = Jumlah anggota cluster ke-i

$\mathrm{i}, \mathrm{k}=$ Indeks dari cluster

$\mathrm{j}=$ Indeks dari variable

$\mathrm{X}_{\mathrm{kj}} \quad=$ Nilai data ke-k variable ke-j untuk cluster tersebut

3. Untuk menghitung jarak terdekat dengan centroid, dapat menggunakan rumus di bawah ini :

$$
d=\sqrt{\left(x_{i}-s_{i}\right)^{2}+\left(y_{i}-t_{i}\right)^{2}}
$$

Keterangan:

$\mathrm{d}=$ Euclidean Distance

$\mathrm{i} \quad=$ banyak objek

$\mathrm{x}, \mathrm{y} \quad=$ Titik koordinat objek

$\mathrm{s}, \mathrm{t}=$ Titik koordinat centroid

4. Golongkan objek menurut jarak ke centroid terdekat.

5. Lakukan kembali langkah ke-3 dan langkah ke-4 dan iterasi mencapai centroid bernilai optimal.

\section{Tahap Pengumpulan Data}

Penerapan Algoritma K-Means untuk menentukan tingkat kejahatan di tiap Daerah Kota Pematangsiantar dengan memperoleh data dari Hukum Polres Pematangsiantar. Data Kejahatan yang digunakan 
pada penelitian ini adalah data pada Tahun 2019. Dengan demikian, data akan di kelompokkan dengan dua cluster.

\section{HASIL DAN PEMBAHASAN}

Pada Penelitian ini data kriminal ditiap Kecamatan di Pematangsiantar akan dijadikan bahan untuk penerapan data mining. Dalam melakukan clustering, data yang telah diperoleh akan dihitung berdasarkan jumlah data kriminalitas pada tahun 2019 menurut 6 Kecamatan di Wilayah Hukum Polres Pematangsiantar. Berikut data kriminalitas pada tahun 2019:

Jenis kejahatan yang sering terjadi pada tahun 2019 di tiap Daerah Kota Pematangsiantar ialah pembunuhan, pencurian, narkoba, dan pemerkosaan. Dengan penjelasan sebagai berikut:

1. Siantar Martoba di tahun 2019 memiliki 47 kejahatan yang terjadi diantaranya :

Pembunuhan $=10$, Pencurian $=25$, Narkoba $=$ 12, Pemerkosaan $=0$

2. Siantar Timur di tahun 2019 memiliki 40 kejahatan yang terjadi diantaranya :

Pembunuhan $=2$, Pencurian $=16$, Narkoba $=$ 17, Pemerkosaan $=5$

3. Siantar Barat di tahun 2019 memiliki 36 kejahatan yang terjadi diantaranya :

Pembunuhan $=9$, Pencurian $=10$, Narkoba $=9$, Pemerkosaan $=8$

4. Siantar Selatan di tahun 2019 memiliki 19 kejahatan yang terjadi diantaranya :

Pembunuhan $=2$, Pencurian $=15$, Narkoba $=2$, Pemerkosaan $=0$

5. Siantar Utara di tahun 2019 memiliki 43 kejahatan yang terjadi diantaranya :

Pembunuhan $=10$, Pencurian $=17$, Narkoba $=$ 12, Pemerkosaan $=11$

6. Siantar Marihat di tahun 2019 memiliki 30 kejahatan yang terjadi diantaranya :

Pembunuhan $=3$, Pencurian $=17$, Narkoba $=6$, Pemerkosaan $=4$

Tabel1. Data Kriminal Polres Pematangsiantar

\begin{tabular}{|c|l|c|c|c|c|c|c|}
\hline \multirow{2}{*}{ No } & \multirow{2}{*}{ Wilayah } & \multicolumn{6}{|c|}{ Jumlah Kejahatan Tiap Bulan } \\
\cline { 3 - 8 } & Jan & Feb & Mar & Apr & Mei & Jun \\
\hline 1 & $\begin{array}{l}\text { Siantar } \\
\text { Martoba }\end{array}$ & 4 & 5 & 5 & 4 & 3 & 4 \\
\hline 2 & $\begin{array}{l}\text { Siantar } \\
\text { Timur }\end{array}$ & 4 & 0 & 3 & 3 & 5 & 4 \\
\hline 3 & Siantar & 4 & 8 & 5 & 4 & 1 & 1 \\
\hline
\end{tabular}

\begin{tabular}{|c|l|c|c|c|c|c|c|c|}
\hline \multirow{2}{*}{ No } & \multirow{2}{*}{ Wilayah } & \multicolumn{6}{|c|}{ Jumlah Kejahatan Tiap Bulan } \\
\cline { 3 - 8 } & Jan & Feb & Mar & Apr & Mei & Jun \\
\hline 4 & Barat & & & & & & \\
\hline & $\begin{array}{l}\text { Siantar } \\
\text { Selatan }\end{array}$ & 2 & 2 & 2 & 0 & 1 & 2 \\
\hline 5 & $\begin{array}{l}\text { Siantar } \\
\text { Utara }\end{array}$ & 4 & 7 & 6 & 3 & 4 & 4 \\
\hline 6 & $\begin{array}{l}\text { Siantar } \\
\text { Marihat }\end{array}$ & 4 & 2 & 2 & 0 & 2 & 1 \\
\hline No & Wilayah & \multicolumn{6}{|c|}{ Jumlah Kejahatan Tiap Bulan } \\
\hline 1 & $\begin{array}{l}\text { Siantar } \\
\text { Martoba }\end{array}$ & 4 & 2 & 4 & 5 & 0 & 7 \\
\hline 2 & $\begin{array}{l}\text { Siantar } \\
\text { Timur }\end{array}$ & 7 & 2 & 4 & 6 & 1 & 1 \\
\hline 3 & $\begin{array}{l}\text { Siantar } \\
\text { Barat }\end{array}$ & 6 & 1 & 4 & 1 & 0 & 1 \\
\hline 4 & $\begin{array}{l}\text { Siantar } \\
\text { Selatan }\end{array}$ & 0 & 7 & 2 & 0 & 1 & 0 \\
\hline 5 & $\begin{array}{l}\text { Siantar } \\
\text { Utara }\end{array}$ & 1 & 3 & 3 & 4 & 0 & 4 \\
\hline 6 & $\begin{array}{l}\text { Siantar } \\
\text { Marihat }\end{array}$ & 4 & 3 & 7 & 1 & 3 & 1 \\
\hline
\end{tabular}

Wilayah yang memiliki jumlah kejahatan tiap bulan yang hampir sama akan berada pada kelompok wilayah yang sama. Dan wilayah yang memiliki jumlah kejahatan tiap bulan yang berbeda akan berada pada kelompok wilayah yang berbeda

Data tersebut kemudian memasuki tahap analisa, dari tabel 1 , diantaranya :

Jumlah Cluster : 2

Jumlah Data $: 6$

Jumlah Atribut : 2 (cluster tingkat kejahatan tinggi dan cluster tingkat kejahatan rendah

\section{Iterasi ke-1 :}

1. Menentukan Centroid awal secara random.

$\mathrm{C} 1=$ Siantar Martoba $(4,5,5,4,3,4,4,2,4,5,0,7)$

$\mathrm{C} 2=$ Siantar Selatan $(2,2,2,0,1,2,0,7,2,0,1,0)$

2. Menghitung Centroid terdekat.

data $(1,1)$

$=\sqrt{(4-4)^{2}+(5-5)^{2}+(5-5)^{2}+(4-4)^{2}+(3-3)^{2}+(4-4)^{2}+}$
$=0$

data $(1,2)$

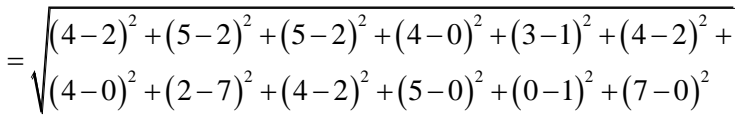

$=12,8840987$ 
data $(2,1)$

$=\sqrt{(4-4)^{2}+(0-5)^{2}+(3-5)^{2}+(3-4)^{2}+(5-3)^{2}+(4-4)^{2}+}$
$=9$

data $(2,2)$

$=\sqrt{(4-2)^{2}+(0-2)^{2}+(3-2)^{2}+(3-0)^{2}+(5-1)^{2}+(4-2)^{2}+}$

$=12,3693169$

$\operatorname{data}(3,1)$

$=\sqrt{(4-4)^{2}+(8-5)^{2}+(5-5)^{2}+(4-4)^{2}+(1-3)^{2}+(1-4)^{2}+}$
$=8,88819442$

$\operatorname{data}(3,2)$

$=\sqrt{(4-2)^{2}+(8-2)^{2}+(5-2)^{2}+(4-0)^{2}+(1-1)^{2}+(1-2)^{2}+}$
$=12,041595$
data(4-0)

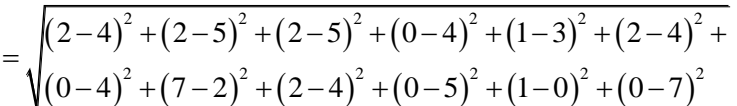
$=12,884099$

data $(4,2)$

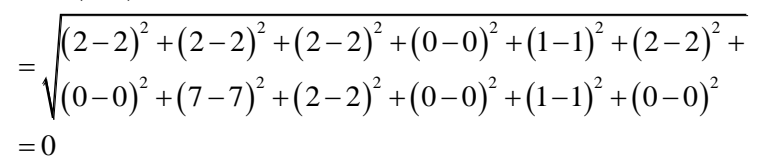

data $(5,1)$

$=\sqrt{(4-4)^{2}+(7-5)^{2}+(6-5)^{2}+(3-4)^{2}+(4-3)^{2}+(4-4)^{2}+}$
$=5,2915026$

data $(5,2)$

$=\sqrt{(4-2)^{2}+(7-2)^{2}+(6-2)^{2}+(3-0)^{2}+(4-1)^{2}+(4-2)^{2}+}$
$=10,86278$

data $(6,1)$

$=\sqrt{(4-4)^{2}+(2-5)^{2}+(2-5)^{2}+(0-4)^{2}+(2-3)^{2}+(1-4)^{2}+}$
$=10,723805$ data $(6,2)$

$$
\begin{aligned}
& =\sqrt{(4-2)^{2}+(2-2)^{2}+(2-2)^{2}+(0-0)^{2}+(2-1)^{2}+(1-2)^{2}+} \\
& =8,30662386
\end{aligned}
$$

3. Setelah proses di atas, maka di lakukan pengelompokkan bedasarkan cluster :

Tabel 3. Hasil Perhitungan Iterasi ke-1

\begin{tabular}{|c|l|c|c|c|}
\hline \multirow{2}{*}{ No } & \multirow{2}{*}{ Wilayah } & \multicolumn{2}{|c|}{ Jarak Ke Centroid } & \multirow{2}{*}{$\begin{array}{c}\text { Jarak } \\
\text { Terdekat }\end{array}$} \\
\cline { 3 - 4 } 1. & $\begin{array}{l}\text { Siantar } \\
\text { Martoba }\end{array}$ & 0 & 12,8840987 & $\mathrm{C} 1$ \\
\hline 2. & $\begin{array}{l}\text { Siantar } \\
\text { Timur }\end{array}$ & 9 & 12,3693169 & $\mathrm{C} 1$ \\
\hline 3. & $\begin{array}{l}\text { Siantar } \\
\text { Barat }\end{array}$ & 8,888194 & 12,0415946 & $\mathrm{C} 1$ \\
\hline 4. & $\begin{array}{l}\text { Siantar } \\
\text { Selatan }\end{array}$ & 12,8841 & 0 & $\mathrm{C} 2$ \\
\hline 5. & $\begin{array}{l}\text { Siantar } \\
\text { Utara }\end{array}$ & 5,2915026 & 10,8627805 & $\mathrm{C} 1$ \\
\hline 6. & $\begin{array}{l}\text { Siantar } \\
\text { Marihat }\end{array}$ & 10,7238053 & 8,30662386 & $\mathrm{C} 2$ \\
\hline
\end{tabular}

4. Selanjutnya adalah menentukan pembaruan centroid dengan menghitung rata-rata nilai pada masing-masing cluster :

Cluster $1=\{$ Siantar Martoba, Siantar Timur, Siantar Barat, Siantar Utara $\}$

$\mathrm{C}_{1}=(4+4+4+4) / 4=4$
$\mathrm{C}_{2}=(5+0+8+7) / 4=5$
$\mathrm{C}_{3}=(5+3+5+6) / 4=4,75$
$\mathrm{C}_{4}=(4+3+4+3) / 4=3,5$
$\mathrm{C}_{5}=(3+5+1+4) / 4=3,25$
$\mathrm{C}_{6}=(4+4+1+4) / 4=3,25$
$\mathrm{C}_{1}=(4+7+6+1) / 4=4,5$
$\mathrm{C}_{8}=(2+2+1+3) / 4=2$
$\mathrm{C}_{1}=(4+4+4+3) / 4=3,75$
$\mathrm{C}_{10}=(5+6+1+4) / 4=4$
$\mathrm{C}_{11}=(0+1+0+0) / 4=0,25$
$\mathrm{C}_{12}=(7+1+1+4) / 4=3,25$

Cluster $2=\{$ Siantar Selatan, Siantar Marihat $\}$
$\mathrm{C} 2{ }_{1}=(2+4) / 2=3$
$\mathrm{C} 2_{2}=(2+2) / 2=2$
$\mathrm{C}_{3}=(2+2) / 2=2$
$\mathrm{C} 2{ }_{4}=(0+0) / 2=0$
$\mathrm{C} 2{ }_{5}=(1+2) / 2=1,5$
$\mathrm{C} 2{ }_{6}=(2+1) / 2=1,5$
$\mathrm{C} 27=(0+4) / 2=2$
$\mathrm{C} 2{ }_{8}=(7+3) / 2=5$ 
$\mathrm{C} 2_{9}=(2+7) / 2=4,5$
$\mathrm{C} 2_{10}=(0+1) / 2=0,5$
$\mathrm{C} 2_{11}=(1+3) / 2=2$
$\mathrm{C} 2_{12}=(0+1) / 2=0,5$

Berdasarkan proses perhitungan di atas, sehingga didapatkan centroid baru untuk iterasi selanjutnya dengan nilai sebagai berikut:

$\mathrm{C} 1=(4,5,4.75,3.5,3.25,3.25,4.5,2,3.75,4,0.25$, $3.25)$

$\mathrm{C} 2=(3,2,2,0,1.5,1.5,2,5,4.5,0.5,2,0.5)$

Selanjutnya proses interasi sampai iterasi 2 seperti dibawah ini:

Tabel 5. Hasil Perhitungan Iterasi ke-2

\begin{tabular}{|c|c|c|c|c|}
\hline \multirow{2}{*}{ No } & \multirow{2}{*}{ Wilayah } & \multicolumn{2}{|c|}{ Jarak Ke Centroid } & \multirow{2}{*}{$\begin{array}{c}\text { Jarak } \\
\text { Terdekat }\end{array}$} \\
\hline & & Cluster 1 & Cluster 2 & \\
\hline 1. & $\begin{array}{l}\text { Siantar } \\
\text { Martoba }\end{array}$ & 4,046604 & 11,1018 & $\mathrm{C} 1$ \\
\hline 2. & $\begin{array}{l}\text { Siantar } \\
\text { Timur }\end{array}$ & 6,919176 & 9,962429 & $\mathrm{C} 1$ \\
\hline 3. & $\begin{array}{l}\text { Siantar } \\
\text { Barat }\end{array}$ & 6,072479 & 9,962429 & $\mathrm{C} 1$ \\
\hline 4. & $\begin{array}{l}\text { Siantar } \\
\text { Selatan } \\
\end{array}$ & 10,71798 & 4,153312 & $\mathrm{C} 2$ \\
\hline 5. & $\begin{array}{l}\text { Siantar } \\
\text { Utara }\end{array}$ & 4,623311 & 9,962429 & $\mathrm{C} 1$ \\
\hline 6. & $\begin{array}{l}\text { Siantar } \\
\text { Marihat }\end{array}$ & 8,299096 & 4,153312 & $\mathrm{C} 2$ \\
\hline
\end{tabular}

Pembaruan centroid dengan menghitung rata-rata nilai pada masing-masing cluster :

Cluster $1=\{$ Siantar Martoba, Siantar Timur, Siantar Barat, Siantar Utara

$$
\begin{aligned}
& \mathrm{C} 1_{1}=(4+4+4+4) / 4=4 \\
& \mathrm{C}_{2}=(5+0+8+7) / 4=5 \\
& \mathrm{C} 1_{3}=(5+3+5+6) / 4=4,75 \\
& \mathrm{C}_{4}=(4+3+4+3) / 4=3,5 \\
& \mathrm{C}_{5}=(3+5+1+4) / 4=3,25 \\
& \mathrm{C}_{6}=(4+4+1+4) / 4=3,25 \\
& \mathrm{C}_{7}=(4+7+6+1) / 4=4,5 \\
& \mathrm{C}_{8}=(2+2+1+3) / 4=2 \\
& \mathrm{C} 1_{9}=(4+4+4+3) / 4=3,75 \\
& \mathrm{C}_{10}=(5+6+1+4) / 4=4 \\
& \mathrm{C}_{11}=(0+1+0+0) / 4=0,25 \\
& \mathrm{C}_{12}=(7+1+1+4) / 4=3,25
\end{aligned}
$$

Cluster $2=\{$ Siantar Selatan, Siantar Marihat $\}$

$$
\begin{aligned}
& \mathrm{C} 2_{1}=(2+4) / 2=3 \\
& \mathrm{C} 2_{2}=(2+2) / 2=2 \\
& \mathrm{C} 2_{3}=(2+2) / 2=2 \\
& \mathrm{C} 2_{4}=(0+0) / 2=0 \\
& \mathrm{C} 2_{5}=(1+2) / 2=1,5 \\
& \mathrm{C} 2_{6}=(2+1) / 2=1,5 \\
& \mathrm{C} 2_{7}=(0+4) / 2=2 \\
& \mathrm{C} 2_{8}=(7+3) / 2=5 \\
& \mathrm{C} 2_{9}=(2+7) / 2=4,5 \\
& \mathrm{C} 2_{10}=(0+1) / 2=0,5 \\
& \mathrm{C} 2_{11}=(1+3) / 2=2 \\
& \mathrm{C} 2_{12}=(0+1) / 2=0,5
\end{aligned}
$$

Hasil tersebut di atas dibandingkan dengan hasil iterasi ke-1 dan hasilnya adalah sama. Maka, pencarian iterasi dihentikan dan hasil telah ditemukan.

Hasil perhitungan manual K-Means dari data 6 Kecamatan dapat di lihat pada grafik, sebagai berikut

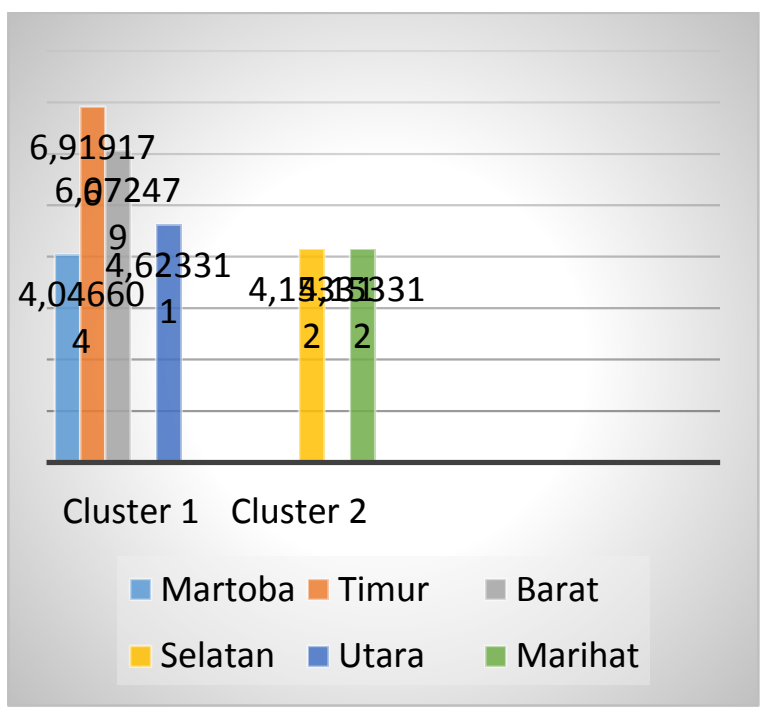

Gambar 2. Cluster Tingkat Kejahatan Tahun 2019.

Hasil yang di dapat dari grafik tersebut yaitu Cluster 1 sebagai tingkat kejahat tinggi dan Cluster 2 sebagai tingkat kejahatan rendah. Dimana Cluster 1 adalah cluster tingkat kejahatan tinggi yakni SIANTAR MARTOBA, SIANTAR TIMUR, SIANTAR BARAT, SIANTAR UTARA dan C2 adalah cluster tingkat kejahatan rendah, yakni SIANTAR SELATAN dan SIANTAR MARIHAT.

\section{KESIMPULAN}

Dari penilitian ini, tingkat keamanan di wilayah Hukum Polres Pematangsiantar berdasarkan jumlah data kejahatan di 6 Daerah Kota Pematangsiantar pada Tahun 2019 dapat disimpulkan bahwa : 
- Pusat cluster pertama berada di Siantar Martoba dan Pusat cluster kedua berada di Siantar Selatan.

- Pusat Cluster pertama memiliki tingkat kejahatan yang paling tinggi di Kota Pematangsiantar.

- Penerapan Algoritma K-Means memperoleh hasil dengan cluster tingkat kejahatan tinggi $(\mathrm{C} 1)=4$ Kecamatan, diantaranya SIANTAR MARTOBA, SIANTAR TIMUR, SIANTAR BARAT, SIANTAR UTARA dan cluster tingkat kejahatan rendah $(\mathrm{C} 2)=2$ Kecamatan, diantaranya SIANTAR SELATAN dan SIANTAR MARIHAT.

\section{DAFTAR PUSTAKA}

[1] S. M. Dewi, A. P. Windarto, I. S. Damanik, and H. Satria, "Analisa Metode K-Means pada Pengelompokan Kriminalitas Menurut Wilayah," Semin. Nas. Sains Teknol. Inf., pp. 620-625, 2019.

[2] L. Suriani, "Pengelompokan Data Kriminal Pada Poldasu Menentukan Pola Daerah Rawan Tindak Kriminal Menggunakan Data Mining Algoritma K-Means Clustering," J. Sist. Komput. dan Inform., vol. 1, no. 2, p. 151, 2020, doi: 10.30865/json.v1i2.1955.

[3] F. Sembiring, O. Octaviana, and S. Saepudin,
"Implementasi Metode K-Means Dalam Pengklasteran Daerah Pungutan Liar Di Kabupaten Sukabumi (Studi Kasus: Dinas Kependudukan Dan Pencatatan Sipil)," J. Tekno Insentif, vol. 14, no. 1, pp. 40-47, 2020, doi: 10.36787/jti.v14i1.165.

[4] R. T. Vulandari, "Pengelompokan Tingkat Keamanan Wilayah Jawa Tengah Berdasarkan Indeks Kejahatan Dan Jumlah Pos Keamanan Dengan Metode Klastering K-Means," J. Ilm. SINUS, vol. Vol 14, No, no. ISSN :1693-1173, pp. 59-72, 2016.

[5] M. Simanjuntak and Dkk, "Penerapan Data Mining Pengelompokan Kejahatan Elektronik Sesuai UU ITE dengan Menggunakan Metode Clustering," J. Mahajana Inf., vol. 3, no. 2, p. 3, 2018.

[6] J. W. Anggoro, M. Awaluddin, and A. L. Nugraha, "Jurnal Geodesi Undip Oktober 2019 Jurnal Geodesi Undip Oktober 2019," Geod. Undip, vol. 8, pp. 225-234, 2019.

[7] R. A. Margolang, S. R. Andani, and M. R. Lubis, "Implementasi Data Mining dalam Mengelompokkan Rumah Tangga Kumuh di Perkotaan Berdasarkan Provinsi Menggunakan Algoritma K-Means," Pros. Semin. Nas. Ris. Inf. Sci., vol. 1, no. September, p. 602, 2019, doi: 10.30645/senaris.v1i0.66. 